\title{
A HISTOMORPHOMETRIC META-ANALYSIS OF SINUS ELEVATION WITH VARIOUS GRAFTING MATERIALS
}

\author{
Amr El Sayed El Balka *, Ibrahim Abdallah ${ }^{* *}$ and Tarek Elghareeb ${ }^{* * *}$
}

\begin{abstract}
Several grafting materials have been used in the sinus floor augmentation procedures including autogenous bone (AB), Xenograft (Bio-Oss), inorganic bovine bone (ABB), platelet rich fibrin (PRF), plasma rich fibrin (PRF), hydroxy appatite (HA), calcium sulfate and pegen P15 used AB as a comparator and the other six materials as interventions. Up to now a subject of controversy in maxillofacial surgery and dentistry is what is the most appropriate graft material for sinus floor augmentation. Materials and Methods: The literature searches were performed using PubMed search. The search covers only English, human and RCT literatures. For analyzing the quality and quantity of bone. After search strategy on PubMed we found 336 articles then after applying the inclusion and exclusion criteria the remaining RCT articles which met the criteria are 2 studies, which measures the bone quality only by Histomorphometric and no included RCT paper using CBCT. Results: In the remaining 2 articles the comparison occur between 2 materials which are autogenous bone and Bio-Oss using Histomorphometric analysis on 48 patients, which gives result in the first study $\mathrm{AB}=37.7 \pm 31.3 \%$, Bio-Oss $=41.7 \pm 26.6 \%$ and in the second study $\mathrm{AB}=42.74 \pm 2.10 \%$, Bio-Oss $=24.90 \pm 5.76 \%$. Conclusion: The bone quality formed by Bio-Oss is less than autogenous bone by $17.1 \%$ so that the autogenous bone remains the gold standard grafting material.
\end{abstract}

\section{INTRODUCTION}

Several grafting materials have been used in the sinus floor augmentation procedures including autogenous bone(AB), Xenograft (Bio-Oss), inorganic bovine bone $(\mathrm{ABB})$, platelet rich fibrin (PRF), plasma rich fibrin (PRF), hydroxy appatite (HA), calcium sulfate and pegen P15 used AB as a comparator and the other six materials as interventions. Up to now a subject of controversy in maxillofacial surgery and dentistry is what is the most appropriate graft material for sinus floor augmentation.

\section{Purpose:}

The aim of the study is to provide a body of evidence-based data regarding grafting materials in sinus floor elevation concerning the quality of bone which measured by Histomorphometric analysis

\footnotetext{
* Master Candidates, Oral and Maxillofacial Surgery Department, Faculty of Dentistry, Cairo University

** Professor of Oral and Maxillofacial Surgery, Faculty of Dentistry, Cairo University

*** Assistant Professor of Oral and Maxillofacial Surgery, Faculty of Dentistry, Cairo University
} 
and the quantity of bone which measured by Cone Beam Computed-Tomography (CBCT), through a meta-analysis of the available literature.

\section{MATERIALS AND METHODS}

The literature searches were performed using:

Electronic searching on PubMed Search from (2000 to 1st of March 2017), Cochrane Oral Health Group Trials Register

And Hand searching on The following journals were searched:International journal of oral maxillofacial, British Journal of Oral Maxillofacial, Europe Journal of Oral and Maxillofacial Surgery.

The search covers Sinus graft on adult $>18$ years with various material Xenograft or Platelet rich fibrin or Plasmarich fibrin or Hydroxy appatite or Calcium sulfate or pepgen $\mathrm{P} 15$ or all of them versus autogenous bone With follow up period for 8.5 months postoperatively after any intervention , only English, human and RCT literatures. For analyzing the quality and quantity of bone., ${ }^{1,2}$ After search strategy on PubMed we found 336 articles then after applying the inclusion and exclusion criteria the remaining RCT articles which met the criteria are 2 studies, which measures the bone quality only by Histomorphometric and no included RCT paper using CBCT. ${ }^{3,4}$

\section{RESULTS}

The search strategy retrieved 336 (PubMed, MEDLINE) references to studies, after initial literature search. Three of these were written in non-english and another four were animal studies, so the remaining articles were 329 . Then we exclude the articles which not make sinus lift and do not use any of the wanted materials in the study are 38 articles, so the remaining 291. After that we exclude the article which uses only one type of graft materials which are 88 articles, so the remaining become 203. Subsequently we exclude the articles which make comparisons between two materials at least and autogenous bone not one of them which are 93 articles, so the remaining 110. As well we exclude the articles which use mixture of materials without using the autogenous bone versus one of the six materials which are 76 , so the remaining 34 .

Then we exclude the studies according to type of the study we take the randomized clinical trials which are five articles and the prospective studies which are one article and exclude the remaining articles which are 30 articles. After that we exclude other articles which not measure the amount of bone according to cone beam CT and histomorphometry tests, so the remaining articles which measuring the amount of bone formed after graft by histomorphometry only 2 articles and no articles use cone beam CT, so the final results are 2 articles

\section{These 2 articles are:}

1. Histological results after maxillary sinus augmentation with Straumann ${ }^{\circledR}$ BoneCeramic, Bio-Oss ${ }^{\circledR}$, Puros ${ }^{\circledR}$, and autologous bone. A randomized controlled clinical trial. ${ }^{5}$

2. A clinical and histologic evaluation of implant integration in the posterior maxilla after sinus floor augmentation with autogenous bone, bovine hydroxyapatite, or a 20:80 mixture. ${ }^{6}$ 


\section{Data outcomes}

\begin{tabular}{|l|l|l|l|l|l|}
\hline \multicolumn{2}{|c|}{} & \multicolumn{2}{|l|}{ Study 1 } & \multicolumn{2}{l|}{ Study2 } \\
\cline { 3 - 6 } \multicolumn{2}{|c|}{} & Number of patients & Result & Number of patients & Result \\
\hline \multirow{3}{*}{ Outcome } & I 1 & 10 & $41.7 \pm 26.6 \%$ & 15 & $24.90 \pm 5.67 \%$ \\
\cline { 2 - 6 } & C 1 & 11 & $37.7 \pm 31.3 \%$ & 12 & $42.74 \pm 2.10 \%$ \\
\hline
\end{tabular}

Studies reported about bone quality using cone beam $C T$.

Meta analysis of the outcomes

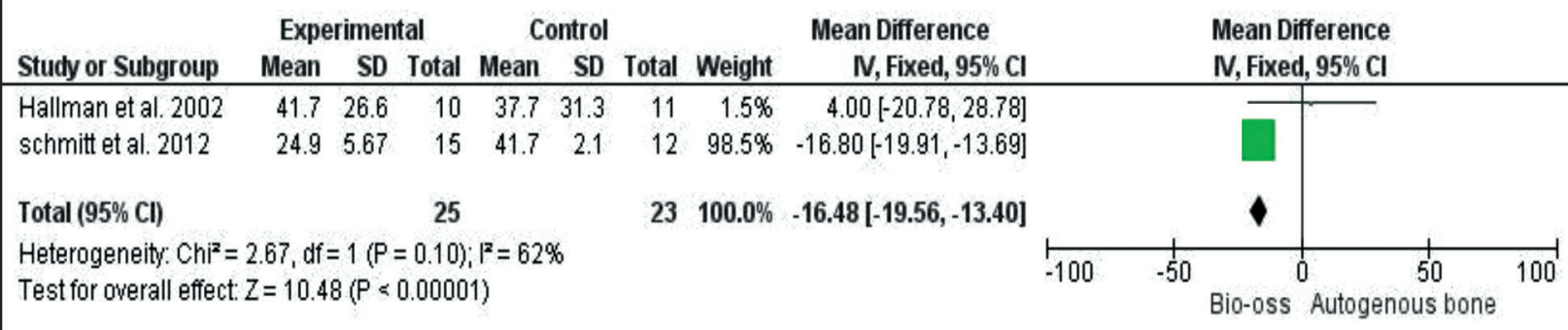

Since $\mathrm{I}^{2}$ revealed marked heterogeneity, we used random effects model.

\section{Random effects meta-analysis}

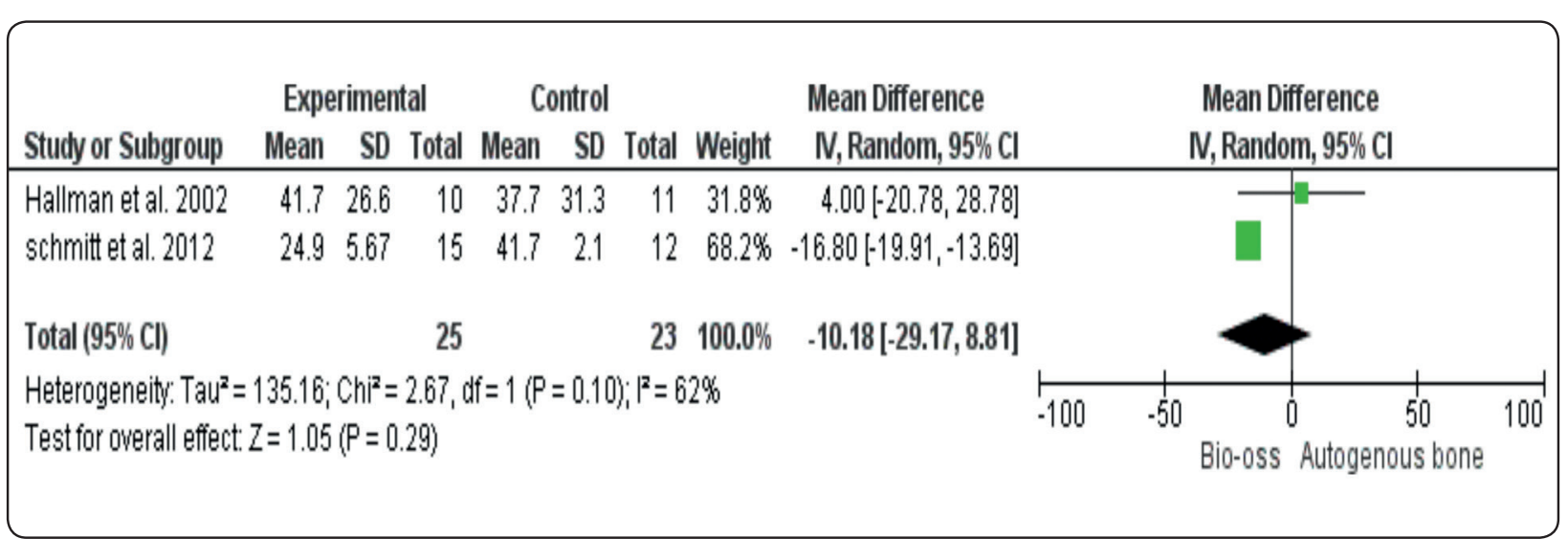

** No other analyses were attempted due to the limited number of obtained studies.

**The overall assessment of the quality of evidence using GRADE is very low 


\section{Risk of bias for the included studies}

The two studies are considered at a high risk of bias

A plot of the distribution of review authjudgements across studies for each risk of bias item

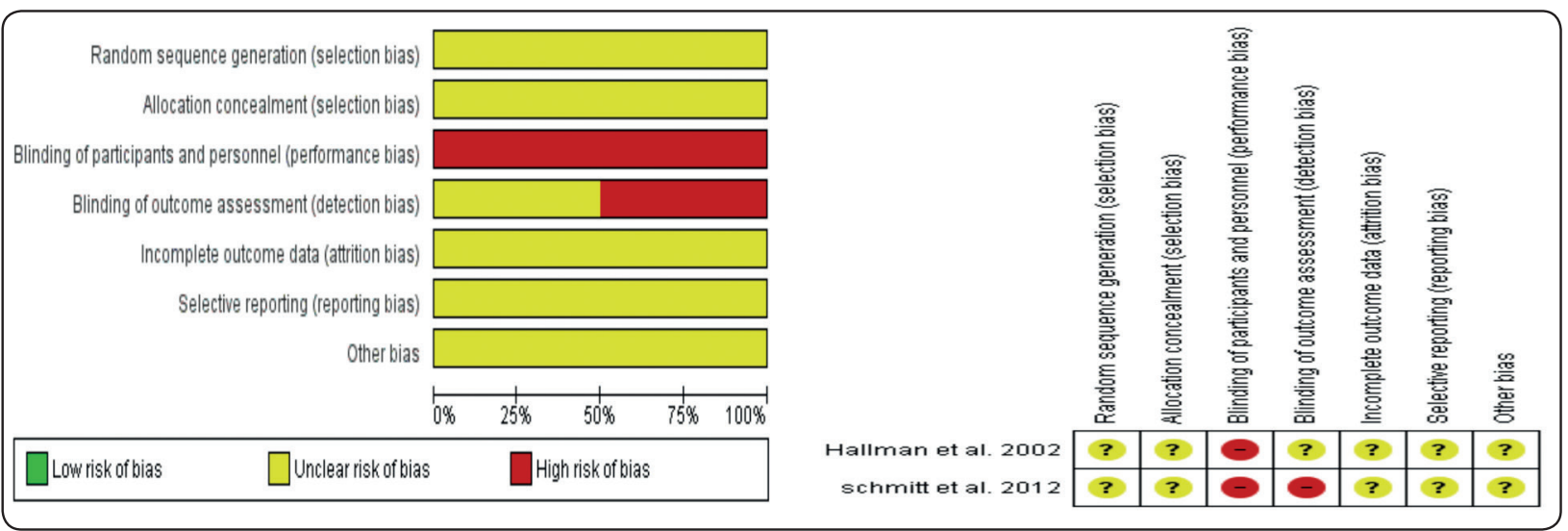

A summary table of review authors' judgements for each risk of bias item for each study

\section{DISCUSSION}

External sinus floor augmentation has proven to be very effective in increasing bone volume in edentulous maxillary areas. Due to the significant resorption in the posterior maxilla following teeth extraction there is often not enough bone volume to ensure the stability of dental implants. Elevation and augmentation of the maxillary sinus can increase the bone height in the posterior area of the maxilla., 7,8

Various bone grafting materials have been used as alternatives or supplements to the autogenous bone such as Xenograft(Bio Oss*), Platelet Rich Fibrin, Plasma rich fibrin, Calcium Sulfate, Hydroxy Appatite and PepGen P15. In order to overcome the previous complications and limitations of autogenous bone graft. ${ }^{10}$

Bone quality and quantity are the most important parameters that are required to contrast different substituting materials to the gold standard autogenous bone graft and also bone quantity and quality are affecting on the implant stability. ${ }^{11}$

The best parameter for measuring the bone quality is histomorphometric analysis and also, we choose $\mathrm{CBCT}$ for measuring the bone quantity. ${ }^{12,13}$

Unfortunately, there were only 2 studies that met the inclusion criteria of this review. RCTs we considered only acceptable since it has 48 patients we included in the studies. Risk of bias assessments for these studies was at high risk.

The 2 studies make comparison between autogenous bone $(\mathrm{AB})$ and Bio-Oss, using Histomorphometric analysis as a measure only.

\section{The results of the two studies on which our re- search based on:}

In the first study (The Schmitt CM, Doering H, Schmidt T, Lutz R, Neukam FW, Schlegel KA, 2012 study) that The amount of newly formed bone in the cranial portion was highest in the $\mathrm{AB}$ group $(42.74 \pm 2.10 \%)$ and for Bio-Oss $(24.90 \pm 5.67 \%)$. In the second study (The Hallamn M, Sennerby L, Lundgren S, 2002 study) that the amount of newly formed bone in the $\mathrm{AB}$ group is $(37.7 \pm 31.3 \%)$ and for Bio-Oss group $(41.7 \pm 26.6 \%)$. Other study give a Histomorphometric result that the autogenous bone group was $(40.1 \pm 3.2 \%)$ and for Bio-Oss group 
$(39 \pm 1.6 \%)$. Another study's Histomorphometric result for autogenous bone group $(49.2 \pm 3.1 \%)$ and for Bio-Oss group $(34.2 \pm 13.1 \%)$. In our research we found that the outcome (Bone Quality) using Histomorphometric analysis was reported, a metaanalysis for this outcome reveals that Bio-Oss bone quality is $16.48 \%$ less than that of the autogenous bone graft. According to that result the clinical importance is that the newly bone formed after grafting with autogenous bone is more mineralized and higher quality than that formed after grafting with Bio-Oss material. The current results of this review were in accordance with Jörg Handschel,et al. and Antonin Simunek et al.

\section{Limitations of this study:}

1. Only two studies were assigned in this review.

2. Both of the included studies are at high risk of bias.

3. No study reported about bone quantity using CBCT.

4. The overall quality of this review is very low.

\section{CONCLUSION}

Based on the quantitative analysis Bone quality associated with Bio-Oss is less than that of the autogenous bone.

Finally, We found that the autogenous bone is still the gold standard grafting material.

\section{Recommendations}

Well-conducted RCTs comparing between the autogenous bone graft and Bio-Oss are required, because the 2 studies which our search based-on have a high risk of bias to give more accurate results and information about this object.

\section{REFERENCE}

1. Matos, S., Aplicação de matrizes enriquecidadas com moduladore biológicos na regeneração de tecidos periodontais e defeitos ósseos. Tese de Doutoramento, 2008.

2. Guerra, F., Biomimética - Formulações haptotáticas para aplicação em regeneração óssea. Tese de Doutoramento, 2003.

3. K. Hashimoto, Y. Arai, K. Iwai, M. Araki, S. Kawashima, and M.Terakado, "Acomparison of a new limited cone beamcomputed tomography machine for dental use with a multidetector row helical CT machine" Oral Surgery, Oral Medicine, Oral Pathology, Oral Radiology, and Endodontics, vol. 95, no. 3, pp. 371-377, 2003.

4. Antonin.S, Dana.K, Rakesh.S, Shirhasha.P and Tomas.B. Deprotonized bovine bone versus B-tricalcium phosphate in sinus augmentation surgery: A Comparative histologic and Histomorphometric study, 2008.

5. Christian Martin Schmitt 1, Hendrik Doering, Thomas Schmidt, Rainer Lutz, Friedrich Wilhelm Neukam, Karl Andreas Schlegel Histological results after maxillary sinus augmentation with Straumann ${ }^{\circ}$ BoneCeramic, Bio-Oss $®$, Puros ${ }^{\circledR}$, and autologous bone. A randomized controlled clinical trial

6. Mats Hallman 1, Lars Sennerby, Stefan Lundgren A clinical and histologic evaluation of implant integration in the posterior maxilla after sinus floor augmentation with autogenous bone, bovine hydroxyapatite, or a 20:80 mixture

7. Eun-S`ik Jang, Jun-Woo Park, Haeyong Kweon, KwangGill Lee, Seok-Woo Kang, Dong-Heon Baek, Je-Yong Choi, Seong-Gon Kim., Restoration of peri-implant defects in immediate implant installations by Choukroun platelet-rich fibrin and silk fibroin powder combination graft. Oral Surg Oral Med Oral Pathol Oral Radiol Endod. 109(6):831-6, 2010.

8. Jorg. H, Melani. S, Christian. N, Rita. D, Micellhe. O, Ulrich. $\mathrm{M}$ and Norbert. K. A Histomorphometric meta-analysis of sinus elevation with various grafting materials, 2009.

9. David W Dempster, Juliet E Compston, Marc K Drezner, Francis H Glorieux, John A Kanis, Hartmut Malluche, Pierre J Meunier, Susan M Ott, Robert R Recker, and A Michael Parfitt., Standardized nomenclature, symbols, and units for bone histomorphometry: a 2012 update of the report of the ASBMR Histomorphometry Nomenclature Committee. J Bone Miner Res. 28(1): p. 2- 17, 2013.

\footnotetext{
* Geistlich Pharma North America Inc. USA
} 
10. Slyfield, C.R., et al., Three-dimensional dynamic bone histomorphometry. J Bone Miner Res. 27(2): p. 486-95, 2012., Three-dimensional dynamic bone histomorphometry. J Bone Miner Res. 27(2): p. 486-95, 2012.

11. Kulak, C.A. and D.W. Dempster, Bone histomorphometry: a concise review for endocrinologists and clinicians. Arq Bras Endocrinol Metabol. 54(2): p. 87, 2010.

12. Palma, P., Estudo de novas formulações para regeneração óssea e defeitos de dimensão crítica.

13. Anton Friedmann, Asisa Friedmann, Leticia Grize, Marcel Obrecht, Michel Dard., Convergent methods assessing bone growth in an experimental model at dental implants in the minipig. Ann Anat. 196(2-3):p. 100-7, 2014

14. A M Parfitt, M K Drezner, F H Glorieux, J A Kanis, H Malluche, P J Meunier, S M Ott, R R Recker ., Bone histomorphometry: standardization of nomenclature, symbols, and units. Report of the ASBMR Histomorphometry Nomenclature Committee. J Bone Miner Res, 2(6): p. 595610, 1987.

15. Rauch, F., Watching bone cells at work: what we can see from bone biopsies. Pediatr Nephrol. 21(4): p. $457-$ $62,2006$.

16. Samuel P Xavier, Rafael R Dias, Felipe P Sehn, Adrian Kahn, Liat Chaushu, Gavriel Chaushu Maxillary sinus grafting with autograft vs. fresh frozen allograft: a split-mouth histomorphometric study. Clin Oral ImplantsRes, 2014.

17. Gert L de Lange, Janice R Overman , Elisabet FarréGuasch, Clara M Korstjens, Bastiaan Hartman, Geerling E J Langenbach, Marion A Van Duin, Jenneke Klein-Nulend., A histomorphometric and micro-computed tomography study of bone regeneration in the maxillary sinus comparing biphasic calcium phosphate and deproteinized cancellous bovine bone in a 105 human split-mouth model. Oral Surg Oral Med Oral Pathol Oral Radiol. 117(1): p. 8-22, 2014.

18. Cassio Eduardo Raposo-Amaral, Daniela Franco Bueno,Ana Beatriz Almeida, Vanda Jorgetti, Cristiane Cabral Costa, Cecília Helena Gouveia,et.al., Is bone trans- plantation the gold standard for repair of alveolar bone defects Tissue Eng, 2014.

19. Jin-Woo Park 1, Jae-Min Kim, Heon-Jin Lee, Seong-Hwa Jeong, Jo-Young Suh, Takao Hanawa., Bone healing with oxytocin-loaded microporous beta-TCP bone substitute in ectopic bone formation model and critical-sized osseous defect of rat. J Clin Periodontol. 41(2): p. 181-90, 2014.

20. Farhang Alaee Seung-Hyun Hong Alex G. Dukas Michael J. Pensak David W. Rowe Jay R. Lieberman., Evaluation of osteogenic cell differentiation in response to bone morphogenetic protein or demineralized bone matrix in a critical sized defect model using GFP reporter mice. J Orthop Res, 2014

21. Hamdan S Alghamdi, Ruggero Bosco, Sanne K Both, Michele Iafisco, Sander C G Leeuwenburgh, John A Jansen, Jeroen J J P van den Beucken., Synergistic effects of bisphosphonate and calcium phosphate nanoparticles on peri-implant bone responses in osteoporotic rats. Biomaterials. 35(21): p. 5482-90, 2014

22. Sungtae Kim 1, Jung-Seok Lee, Ji-Wan Hwang, Min-Soo Kim, Seong-Ho Choi, Ui-Won Jung., Reosseointegration of mechanically disintegrated implants in dogs: mechanical and histometric analyses. Clin Oral Implants Res. 25(6): p. 729-34, 2014.106

23. Y. Arai, E. Tammisalo, K. Iwai, K. Hashimoto, and K. Shinoda,"Development of a compact computed tomographic apparatus for dental use," Dentomaxillofacial Radiology, vol. 28, no. 4, pp.245-248, 1999.

24. K. Ito, Y. Gomi, S. Sato, Y. Arai, and K. Shinoda, "Clinical application of a new compact CT system to assess 3-D images for the preoperative treatment planning of implants in the posterior mandible: a case report," Clinical Oral Implants Research, vol. 12,no. 5, pp. 539-542, 2000.

25. Y. Nakagawa, K. Kobayashi, H. Ishii et al., "Preoperative application of limited cone beam computerized tomography as an assessment tool beforeminor oral surgery," International Journal of Oral and Maxillofacial Surgery,vol. 31, no. 3, pp. 322-327, 2002. 